\title{
Numerical Analysis of Blast Pressure Distribution on RC Wall Surface
}

\author{
M A Seman, S M Syed Mohsin, Z M Jaini
}

\begin{abstract}
Three-dimensional (3D) numerical modelling of blast subjected to reinforced concrete wall is studied in this paper. The Arbitrary Lagrange Euler (ALE) solvers approach is employed for the interface analysis between air and structure in AUTODYN commercial software. The previous published empirical and semi empirical methods are compared on the blast pressure profile impacted on the wall surface. Besides, the effects of air volume size, the effects of air grid mesh refinement also assessed. Initially, the $3 D$ numerical blast pressure is validated with the blast pressure test conducted at Fort Leonard Wood Army Base for further blast pressure investigation. From series of simulation conducted, the blast pressure at the bottom part on the wall surface experienced the highest pressure. Contrary on the empirical and semi empirical, the blast pressure distribution is identical either at the top or bottom surface of the wall.
\end{abstract}

Keywords: AUTODYN, Blast, Reinforced Concrete, Simulation.

\section{INTRODUCTION}

Aggressors attack using improvised explosive not the only source for the blast load. Some commercial equipment and human daily activities can contribute as well, such as electrical transformer, gas pipelines and industrial plants. The explosion generates overpressure, which may injure people and damage any object on it path. Generally, the pressure propagates radially in all direction from the explosion centre at supersonic speed. Prior studies on the blast pressure on object have been undertaken over the past half century [1-6]. Basically, the recommended expression is based on standoff distance and charge weight as an equivalent mass of Trinitrotoluene (TNT) to predict the blast peak overpressure. The reflected overpressure resulted from the reflection wave due to obstacle also been modeled [6]. Besides the empirical expressions, the Unified Facilities Criteria (UFC) manuals are widely used for blast pressure parameters. The manuals contain data on explosive tests using charge weight from less than $1 \mathrm{~kg}$ up to $400,000 \mathrm{~kg}$ [7-8]. Nowadays, with the rapid development of computer technology and advancement of numerical techniques over the last decades, it makes the predictions of blast pressure-time history in related engineering problems are viable [9].

Revised Manuscript Received on November 05, 2019.

* Correspondence Author

M A Seman*, Faculty of Civil Engineering Technology, Universiti Malaysia Pahang, Gambang, Kuantan Pahang, Malaysia. Email: mazlanseman@ump.edu.my

S M Syed Mohsin, Faculty of Civil Engineering Technology, Universiti Malaysia Pahang, Gambang, Kuantan Pahang, Malaysia. Email: maszura@ump.edu.my

Z M Jaini, Faculty of Civil Engineering and Environmental Engineering, Universiti Tun Hussein Onn Malaysia, Batu Pahat, Johor, Malaysia. Email: rizuan@uthm.edu.my
A blast wave originating from closed or free explosion detonation behaves, when interacting with structures, as a short duration dynamic load. Previous studies have shown that load with short duration and high magnitude influence significantly the response of the structure and can modify substantially the expected material behaviour. For the explosive with close standoff distance from the wall, there is no pressure gauge mounted on the wall side to measure the blast overpressure. This is probably due to the fact of the fear of the gauge being damaged, the difficulty in keeping the gauge steady during the blast test and also the fact that the gauge may receive both incipient and reflected shock waves. Therefore, the pressure data acquired directly from the wall face may not be credible [10]. Therefore, the interest of this paper is to appraise the blast parameters impacted on the structure. In this paper, numerical methods are used to appraise and validate the overpressure parameter for the same charge weight and specific distance as published in previous research. Then further numerical blast pressure profile impacted on the wall surface will be assessed.

\section{BLAST PRESSURE PROFILE}

The blast pressure profile for varies and different sources of origin which are categorised as high explosive (HE) such as conventional bomb and vehicle bomb having typical shape as shows in Fig.1. Before the shock front reaches the given point, the ambient pressure is $p_{o}$. At arrival time $t_{\mathrm{a}}$, the pressure rises discontinuously to the peak value of $p_{o}+P_{s}^{+}$. The quantity $P_{s}^{+}$ is called the peak overpressure. The pressure then decays to ambient in a total time of $t_{\mathrm{a}}+T$, and then drops to a partial vacuum of value $p_{o}-P_{s}^{\square \square}$, and eventually returns to the ambient pressure $p_{o}$, in a total time of $t_{\mathrm{a}}+T+T$. The pressure-time history of the blast wave is often described by exponential functions such as the Friedlander equation [6].

$$
p(t)=p_{0}+P_{s}^{+}\left(1 \quad t / T^{+}\right) e^{b t / T^{+}}
$$

where $\mathrm{t}$ is the time, $p_{o}$ is the ambient pressure, $p_{s}$ is the peak overpressure, $T_{s}$ is the duration of the positive phase, $t_{a}$ is the arrival time and $b$ is a positive constant of waveform parameter that depends on the peak overpressure. In the blast event, two parameters that the most directly influence the blast environment are the charge weight $W$, and the standoff distance $(R)$ between the blast source and the target. In practice, the charge weight $(W)$ is identified as an equivalent mass of TNT in kilograms. Therefore, for any distance $(R)$ from an explosive charge $(W)$ can be transformed into a characteristic scaled distance $(Z)$ known as scaling laws.

\footnotetext{
Published By:

Blue Eyes Intelligence Engineering
} 
The scaling law provides parametric correlations between a particular explosion and a standard charge of the same substance [11].

$$
Z=R\left(W_{T N T}^{1 / 3}\right)^{1}
$$

According to Department of Defence, USA [8], blast loads can be categorised into two main types based on the confinement environment around the explosive which are, unconfined and confined explosion. The main type can be subcategorised based on blast load produced within the structure or acting on the structures. For unconfined explosions, the blast loading can be subcategorised into free-air explosion, air explosion and surface explosion. While for the confined explosions, it can be fully vented, partially confined and fully confined. According to the present study, unconfined explosion is related and discussed. When an explosion occurs without obstructions in the air medium to amplify the radially propagating blast wave between the explosive charge and structure, the blast load on the structure is free-air explosion. The distance above the ground to the explosive centre usually is about two to three times the height of structure [8]. An air explosion produces by the explosive above the ground and at distance away from the structure, the initial blast wave, propagating away, impinges on the ground surface prior arrival at the structure. If the explosive charge is located above the ground at the height of burst (HOB) within 1-2 meter, the blast is considered as a surface explosion. The initial incident blast waves of the explosion are reflected and amplify by the ground surface to produce a reflected blast wave. Therefore, the blast wave front forms a hemispherical blast wave that propagates toward the target. Surface explosion is different from an air explosion, where the incident and reflected blast wave merge instantly [12-13].

A correlation between surface (hemispherical) explosion and free-air (spherical) explosion, if the ground surface were a perfect reflecting surface, the explosive charge weight for surface explosion would be effectively double. However, due to the energy dissipated in producing a ground crater and ground shock, a multiplier approximately 1.7-1.8 [13-14]. When an explosion occurs with an obstruction to the propagating blast wave such as wall structure, as the blast wave strike the wall surface at a normal angle of incidence $(\alpha)$, the incident overpressure is magnified because the blast wave propagation through the air suddenly arrested and redirect by the wall surface. This resulting the reflected overpressure $\left(P_{r}\right)$ is 2-8 times higher as reported by ASCE [15], while as mentioned by Uddin [13] can be up to 13 times higher. The highest can be up to 20 times than the incident overpressure [16-17].

The angle of incidence $(\alpha)$ of a point on a surface is the angle between the outward normal and the direct vector from explosive charge to the point as illustrated in Fig.2. For the given scaled distance and angle of incidence is zero $(\alpha=0)$, it is fully reflected overpressure. Equation (3) indicates the effective distance $\left(R_{e}\right)$ based on angle of incident. The peak incident overpressure remains close to its fully reflected value if the angle of the incident less than 45 degree according to Remmenikov [12] and also can be estimated by analysing the reflected pressure-angle of incidence relationship curve in UFC 3-340-2 [8].

$$
R_{e}=\left(R^{2}+h^{2}\right)^{1 / 2}
$$

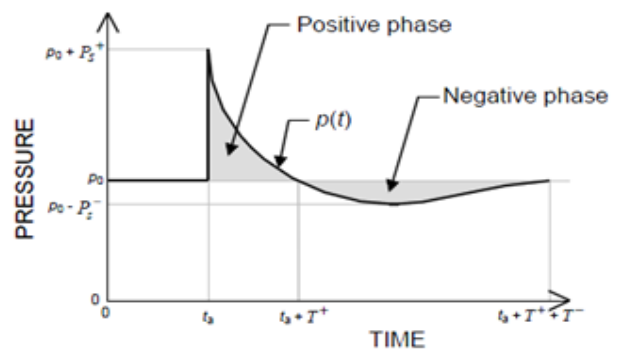

Fig. 1.Pressure-time history of an ideal blast pressure

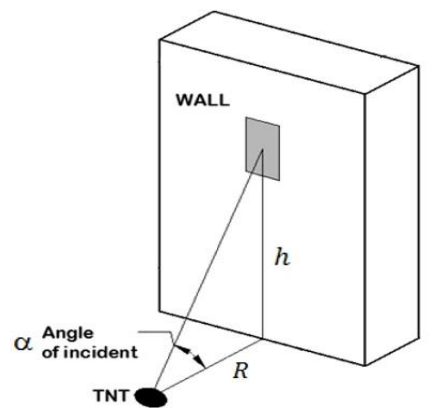

Fig. 2.Angle of incident and actual effective distance

\section{PREDICTION OF BLAST PRESSURE}

There are many solutions proposed for the prediction of blast wave parameters studies, mainly can be divided into (1) analytical or empirical methods: correlations with experimental data. Most of the approaches are limited by underlying experimental database; (2) semi empirical methods: based on simplified model of physic phenomena. These methods rely on extensive data and case study; (3) numerical analysis: based on mathematical equations that describe the basic law of physic. Include conversion of mass, momentum and energy.

\section{A. Empirical}

The empirical method most widely used is manuals based on Department of Defense, USA known as Unified Facilities Criteria (UFC). UFC 3-340-2 [8] used to both military and civilian sectors for designing structures to provide protection against the blast effect of accidental explosion. The design curves presented in the manual give the blast pressure parameters in the function of scaled distance $\mathrm{Z}$ for all unconfined explosions such as peak overpressure $\left(\mathrm{P}_{\mathrm{so}}\right)$, peak reflected overpressure $\left(\mathrm{P}_{\mathrm{r}}\right)$ and time of arrival $\left(\mathrm{t}_{\mathrm{a}}\right)$. Besides UFC 3-340-2, UFC 3-340-1 [7], it is intended for designing hardened facilities to resist the effect of conventional weapons. This includes criteria for protection against penetrating weapons, contact detonation, and blast and fragmentation from a standoff distance. However, this manual is restricted document and for official use only. 
Kingery and Bulmash [4] developed the equation to predict blast parameters from spherical air explosion and hemispherical surface explosion. The equations have been automated in computer program known as Conventional Weapons Effect (ConWep). ConWep is a collection of conventional weapons effect calculation from the equation and curves of UFC 3-340-1. Unlike UFC 3-340-1, where the approximation equivalent triangular pulse is proposed to present the decay of overpressure and reflected overpressure, a realistic approach in assuming an exponential decay of the pressure with time is taken for ConWep as;

$$
P_{t}=P_{s o}\left(1 \frac{t t_{a}}{t_{o}}\right) \exp \left(\frac{b\left(\begin{array}{ll}
t & t_{a}
\end{array}\right)}{t_{o}}\right)
$$

where $P(t)$ is the pressure at time $\mathrm{t}(\mathrm{kPa}) ; P_{\mathrm{so}}$ is the peak incident pressure $(\mathrm{kPa}) ; t_{o}$ is the positive phase duration (msec); $b$ is the decay coefficient (dimensionless); and $t_{a}$ is the arrival time ( $\mathrm{msec})$. The above equation is usually referred to as the Friedlander equation. These equations are widely accepted as engineering predictions for determining free-field pressures and loads on structures. The correlations between decay coefficient $b$ and scaled distance $\mathrm{Z}$ as [18];

$$
b=Z^{2} \quad 3.7 Z+4.2
$$

\section{B. Numerical}

Methodology Numerical simulation is one of the methods to replace an expensive blast test currently. The AUTODYN [9] simulation package is used in the present study. AUTODYN is an integrated explicit analysis tool program specially designed for modelling non-linear dynamic problems that uses finite element, finite volume and mesh-free particle to solve nonlinear dynamic problems of solid, fluids, gas and their interactions. Besides as an integrated explicit analysis tool program, AUTODYN also offers multi-solver coupling for multi-physic including coupling between FE, CFD and SPH.

The Arbitrary Lagrange Euler (ALE) is the numerical approach for the interface analysis between the air and structure. This approach allows different part of the solvers such as structure, fluids and gases can be modeled simultaneously using Lagrange and Euler approaches. These different solvers are then coupled together in space and time. For the Euler solver in the numerical model, air is modelled by an ideal gas EOS, which is one of the simplest forms of EOS. The pressure is related to energy is given by

$$
p=(1) e
$$

where $\lambda$ is a ratio of spesific heat and $\rho$ is air density. $e$ is the spesific internal energy, with the gamma law EOS under standard atmosphere pressure and $\gamma=1.4$, its initial energy is $e=2.068 \times 10^{5} \mathrm{~kJ} / \mathrm{kg}$. In the simulation, the standard constants of air from the AUTODYN material library [9] are used. TNT the high explosives are typically modelled by using the Jones-Wilkins-Lee (JWL) EOS, which model the pressure generated by chemical energy and can be represent as follows

$$
P=A\left(1 \frac{}{R_{1} V}\right) e^{R_{1} V}+B\left(1 \frac{}{R_{2} V}\right) e^{R_{2} V}+\frac{E}{V}
$$

where $\mathrm{P}$ is the detonation of high explosive; $\mathrm{V}$ is the specific volume; $\mathrm{E}$ is specific internal energy; and $A, B, R_{1}, R_{2}$ and and $\omega$ are material constant. In the present simulation, for the TNT explosive charge, $A, B, R_{1}, R_{2}$ and $\omega$ are $3.7377 \times 10^{5} \mathrm{MPa}$, $3.747 \times 10^{3} \mathrm{MPa}, 4.15,0.9$ and 0.35 , respectively.

\section{BLAST PRESSURE IMPACTED ON STRUCTURE}

In the present study, the experimental result of the reinforced concrete (RC) wall structure subjected to blast load [10] was appraised based on the blast pressure parameter. Fig. 3 shows the geometry and section detail of the wall. The walls have a cross-sectional dimension of $1829 \mathrm{~mm} \times 1219$ $\mathrm{mm}$ with wall thickness of $152 \mathrm{~mm}$ and $305 \mathrm{~mm}$ thickness of footing. According to the study, the wall was tested with 4 lbs., $10 \mathrm{lbs}$. and $30 \mathrm{lbs}$. TNT charge weight with $4 \mathrm{ft}$. standoff distance from the centre of the wall. Pressure transducers were placed $18 \mathrm{ft}$. away from the centre of the charge weight. From the blast test conducted, it was revealed, only after the third test with $30 \mathrm{lbs}$. TNT charge weight, the visible cracks were clearly observed on the front and the back of the wall. The recorded peak overpressure was $0.49 \mathrm{MPa}$ at $4.64 \mathrm{msec}$. Therefore, in the present study, the highest charge weight and overpressure parameters are considered in the following numerical appraisal.

In the numerical modelling, the RC structure is modeled as Langrange solver. To describe the concrete behavior under blast load, the material model developed by Riedel, Hiermayer and Thoma (RHT) [19] is adopted. The RHT concrete model is an advanced plasticity model for brittle materials. Particularly, it is useful for modelling the dynamic loading of concrete. The model includes pressure hardening, strain hardening, strain rate hardening, third invariant dependence for compressive and tensile meridian as well as damage model fo strain softening. This model also employs the $p$ - $\alpha$ equation of state [20] to represent the concrete thermodynamic behaviour at high stress, it provides a reasonably detailed description of the compaction behaviour at low-stress ranges. While, for steel reinforcement, Johnson-Cook (JC) material model [21] was used. This model represents the strength behaviour of material subjected to large strain, high strain rates and high temperature, typically metal. Fig. 4 shows the pressure gauge located on the $\mathrm{RC}$ wall. 


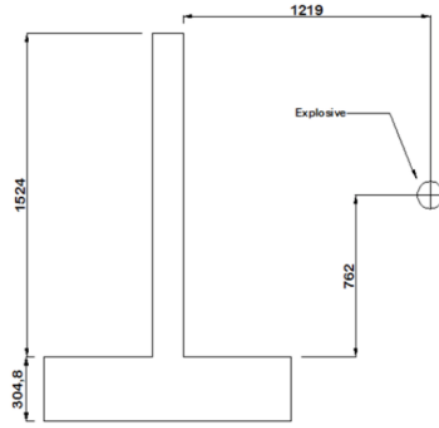

Fig. 3. Geometry of reinforced concrete wall (unit in mm)

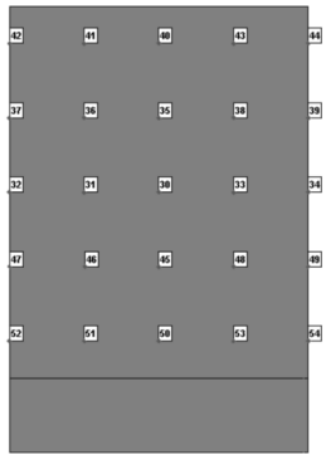

Fig. 4. Pressure gauge on the wall front surface

\section{BLAST PRESSURE ANALYSIS}

\section{A. Empirical}

According to the explosive located in the experimental [10], the blast is categorised as surface explosion. Therefore, the blast pressure parameter for hemispherical explosion in UFC 3-340-2 is used for the analysis. Angle of incident $(\alpha)$ and actual effective distance $\left(\mathrm{R}_{\mathrm{e}}\right)$ are considered for the blast pressure mapping on the wall surface. Fig.5 shows, the incident pressure $\left(P_{s o}\right)$ and reflected pressure $\left(P_{r}\right)$ at the point of interest on the wall surface with 1-degree increment for angle of incident $(\alpha)$ until the top edge of the wall with 37,940 $\mathrm{kPa}$ at $0.36 \mathrm{msec}$ and $4,691 \mathrm{kPa}$ at $0.36 \mathrm{msec}$ respectively for the highest pressure [22]. While in Fig.6(a) shows peak pressure distribution on the wall surface and Fig.6(b) shows peak pressure-time history at the centre of the wall analysed by ConWep with $28,960 \mathrm{kPa}$ at $0.39 \mathrm{msec}[10,23]$.

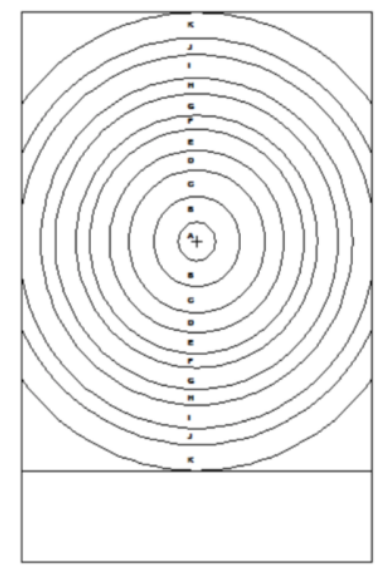

(a)

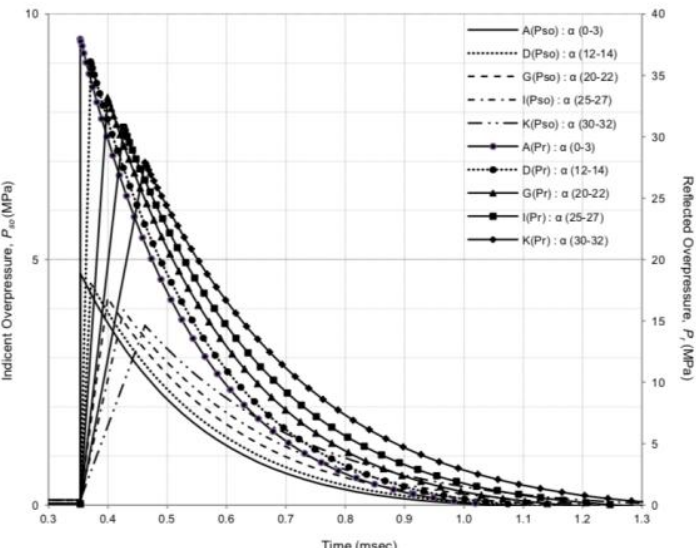

(b)

Fig. 5. Pressure on the wall surface analysed with UFC 3-340-2 (a)Pressure distribution (b)Pressure-time history

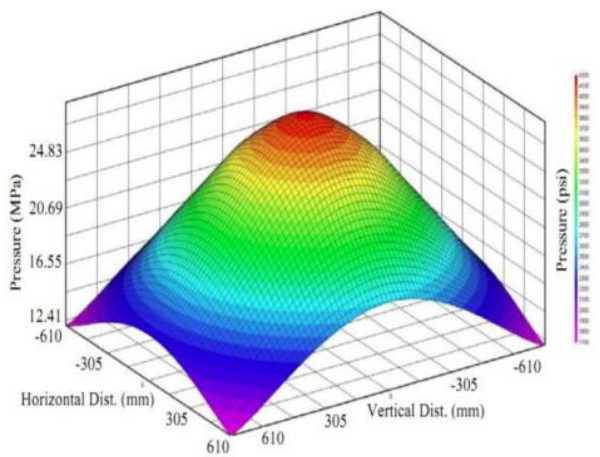

(a)

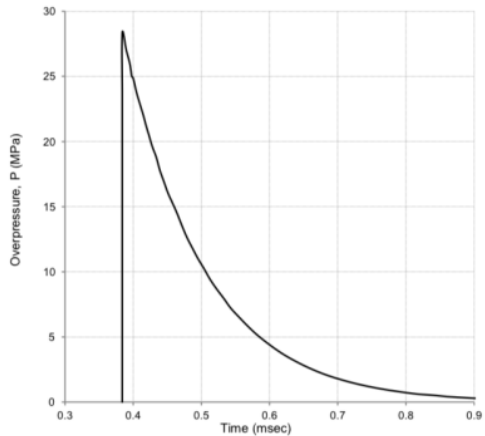

(b)

Fig. 6.Pressure on the wall surface analysed with UFC 3-340-2 or ConWep (a)Pressure distribution. (b)Pressure-time history

\section{B. Numerical}

In order to study the free propagation of the blast waves in the air, a $1 \mathrm{~m} \mathrm{x} 1 \mathrm{~m} \times 5.5 \mathrm{~m}$ (Type 1) air volume was numerically simulated for $30 \mathrm{lbs}$. while TNT charge weight as shows in Fig.7. The wedge consists of blast pressure history is created before the remap function in AUTODYN, as it is used to apply the effect of explosion in 3D model. Gauge 1 and 2 located at $4 \mathrm{ft}$. and $18 \mathrm{ft}$. respectively away from centre of the charge weight. Flow out of air is allowed in all the model borders. The simulation was set up for $25 \mathrm{msec}$, it is found for Gauge 1 the peak incident overpressure is $2,394 \mathrm{kPa}$ at 1.43 msec, while for Gauge 2 is $494.6 \mathrm{kPa}$ at $4.62 \mathrm{msec}$ as shows in Fig.8. From the blast test conducted [10], the peak incident overpressure pressure 
at $18 \mathrm{ft}$. away from centre of explosive recorded is $490 \mathrm{kPa}$ at $4.64 \mathrm{msec}$. Therefore, the numerical results on peak incident overpressure for free field agreed with the experimental conducted.

The same wedge used for remap function above is considered in the numerical simulation of an actual blast test. Fig. 9 shows the location of the gauges in $2.5 \mathrm{~m} \mathrm{x} 2.0 \mathrm{~m} \mathrm{x}$ $12.48 \mathrm{~m}$ (Type 3 ) air volume with the consideration of reinforced concrete wall in the simulation and the same outflow boundaries are assigned. Pressure gauge assigned at 4 $\mathrm{ft}$., $18 \mathrm{ft}$. away from centre of the charge weight and together with gauges on the wall front surface as mentioned earlier. While in Fig.10 shows the RC wall in $2.5 \mathrm{~m} \times 2.0 \mathrm{~m} \times 2.8 \mathrm{~m}$ (Type 4) air volume, where the air volume just covered the structure solvers in the modeling.

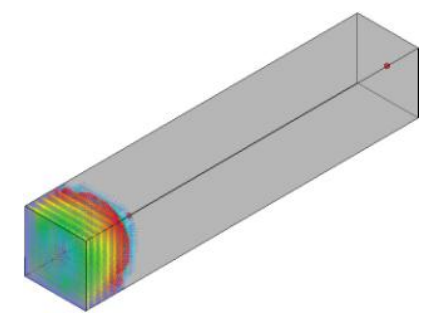

Fig. 7. Blast simulation in free field (Type 1)

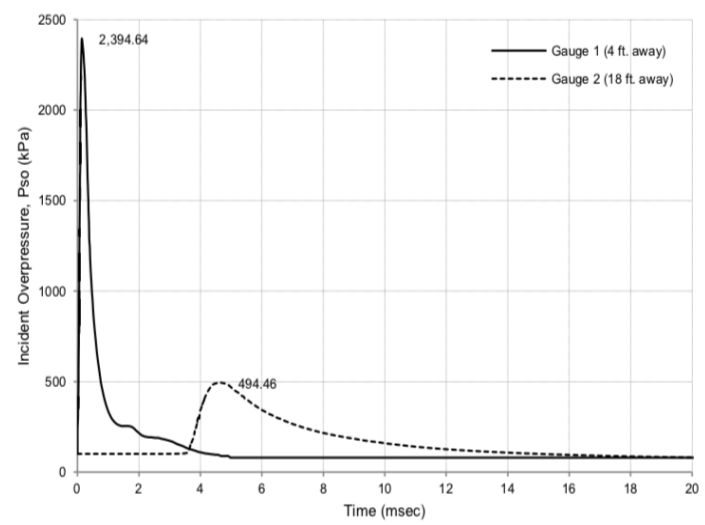

Fig. 8. Blast pressure-time history

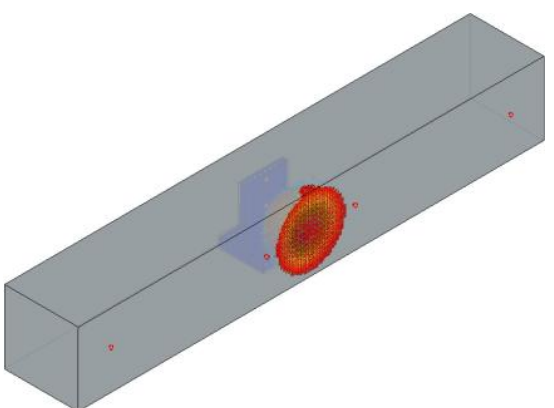

Fig. 9. Model of blast test (Type 3)

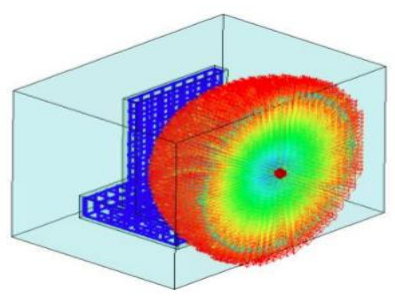

Fig. 10. Model of blast test (Type 4)

\section{PRESSURE IMPACT ON RC WALL}

From series of simulation conducted in AUTODYN, it can be concluded that proper grid size and arrangement on I,J,K directions of the air volume had an important roles in predicting overpressure parameters. Table 1 shows, grid arrangement and pressure at the location of $18 \mathrm{ft}$. away. While, in Fig. 11 shows blast pressure-time history at $18 \mathrm{ft}$. away. A good agreement in maximum peak pressure and time of arrival recorded. Therefore, the peak pressure impacted on the structure is able to appraise.

Fig. 12 shows the overpressure parameters at $4 \mathrm{ft}$. away from explosive center. The analysis of UFC 3-340-2 and ConWep reveals that the pressure is about 4-6 times higher than numerical analysis. This substantially different value might be due to the reflected overpressure curve in the plot which is based on the reflection off an ifinitely large rigid wall to the shock wave. While the wall size of the experimental is significantly smaller compared to the wall tested by Department of Defense, USA [8]. In addition, the numerical simulation of coupled airblast-structure analysis estimates the reduced reflected overpressure computationally. The clearing effect can lead to further reduction of the reflected pressure [24]. Fig.13(a) shows the pressure-time history for each gauges located at the height of $538 \mathrm{~mm}$ (Bottom), $1270 \mathrm{~mm}$ (Middle height) and $1798 \mathrm{~mm}$ (Top edge) from the ground level on the wall surface. It reveals that pressure at the bottom is the highest with $13,981 \mathrm{kPa}$ at $0.25 \mathrm{msec}$. While in Fig.13(b) shows peak pressure distribution impacted on the wall surface. This numerical blast pressure profile impacted on the wall surface proved identical between air volume Type 3 and 4 with the air grid arrangement used.

From the experiment conducted by Yan et al. [10], it is found that the peak strain occured at the bottom of the front face is larger than in the middle height. Generally for the wave propagation, when the shock wave is induced from the explosion, pressure wave will reach the front face first, where a reflection wave will be produced. Besides the reflection wave, part of the wave will also transmit trough the wall, arriving at the back face, another reflection wave and transmission wave will be produced. At the bottom of the wall, in addition of the direct wave and its reflection, the reflection wave of the wave on the base surface will have vital impact on the bottom part of the wall. The combination of these waves at the bottom cause larger deformation at the bottom part of the wall than that in the middle height, where large cracks were observed at the wall-base corner [10,23]. Therefore, it can be said, as the more surface obstruct the wave propagation, the more reflection occurs and magnified the overpressure. Hence, the highest pressure at the bottom gauge and pressure distribution obtained from numerical simulation is proved. In addition, it is also supported with the numerical blast impact on the RC wall as shows in Fig.14 where the damage indicator with mesh of $10 \mathrm{~mm}$ appeared approximately on the reinforcement grid location. 


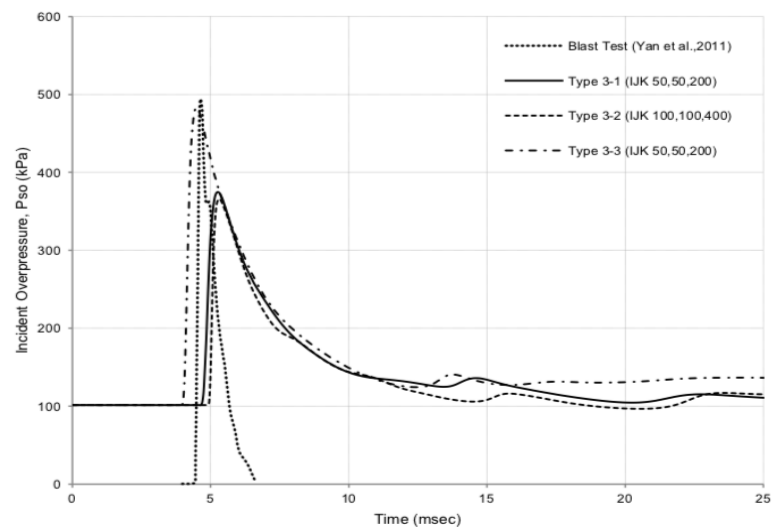

Fig.10. Blast pressure-time history at $18 \mathrm{ft}$. away

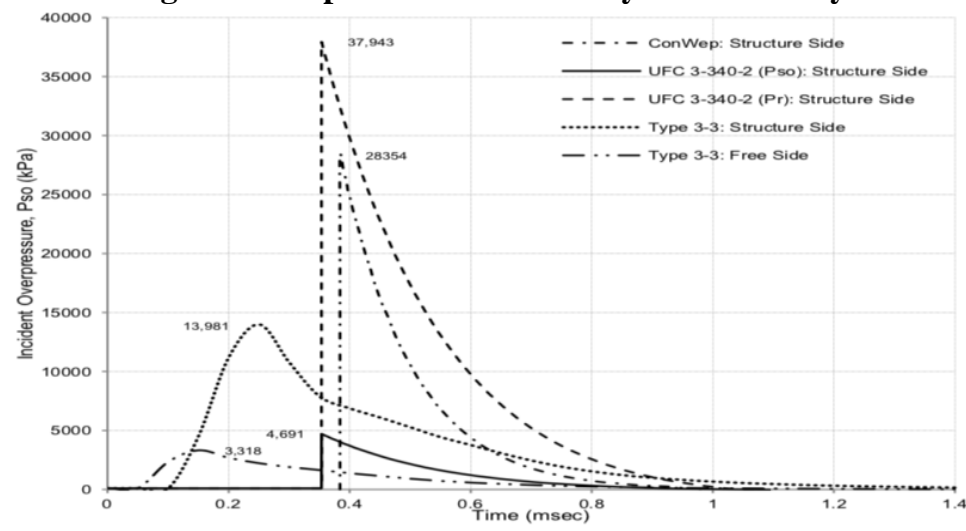

Fig. 12. Peak pressure at $4 \mathrm{ft}$. away

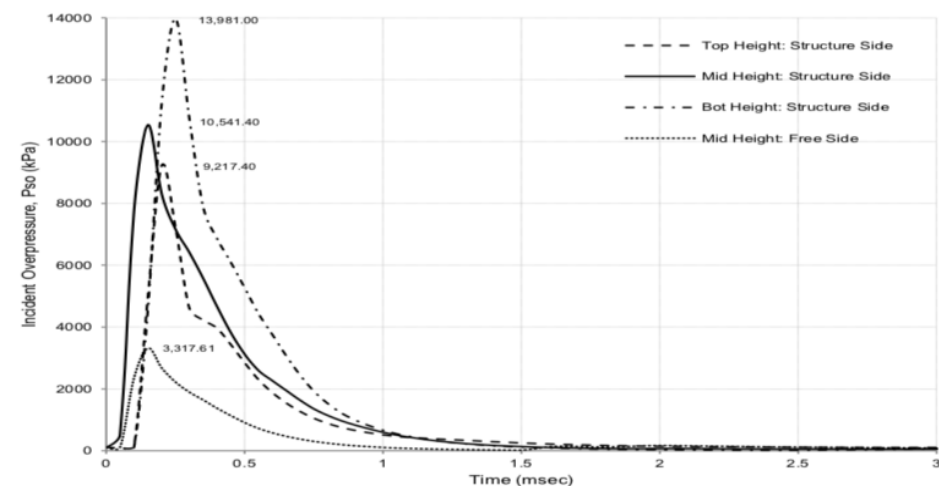

(a)

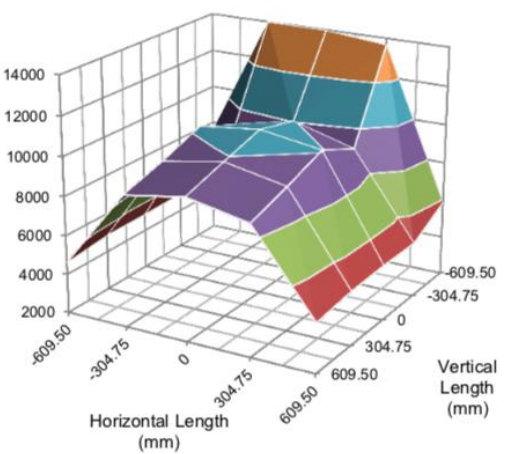

(b)

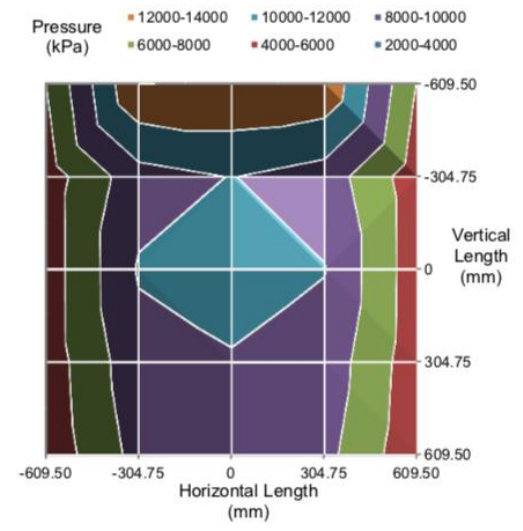

(c)

Fig. 13. Pressure profile on wall surface analysed with AUTODYN (a)Pressure-time history (b)Pressure distribution 
Table- I: Comparison of air type and peak pressure at $18 \mathrm{ft}$. away

\begin{tabular}{cccc}
\hline $\begin{array}{c}\text { Air Type } \\
(\text { Volume })\end{array}$ & $\begin{array}{c}\text { Grid arrangement } \\
(\mathrm{I}, \mathrm{J}, \mathrm{K}) \text { axis }\end{array}$ & $\begin{array}{c}\text { Peak pressure } \\
(\mathrm{kPa})\end{array}$ & $\begin{array}{c}\text { Time of arrival } \\
(\mathrm{msec})\end{array}$ \\
\hline Blast Test [Yan et al] & NA & 490.0 & 4.64 \\
$\begin{array}{c}\text { Type 1 } \\
(1 \mathrm{~m} \times 1 \mathrm{~m} \times 5.5 \mathrm{~m}) \\
\text { Type 3 } \\
(2.5 \mathrm{~m} \times \text { 2.0m } \times 12.48 \mathrm{~m}) \\
\text { Type 4 }\end{array}$ & $(30,30,30)$ & 494.6 & 4.62 \\
$(2.5 \mathrm{~m} \times 2.0 \mathrm{~m} \times 2.8 \mathrm{~m})$ & $(50,50,200)$ & 477.0 & 4.60 \\
\hline
\end{tabular}

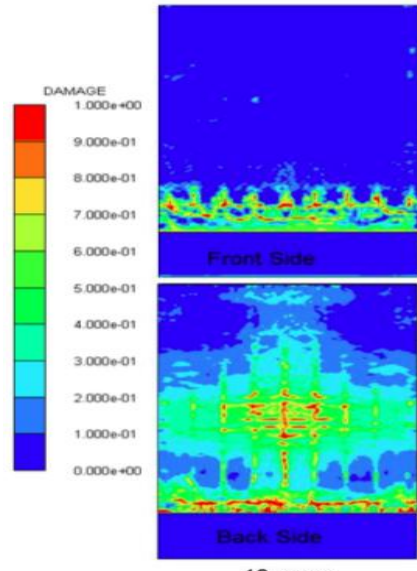

$10 \mathrm{msec}$

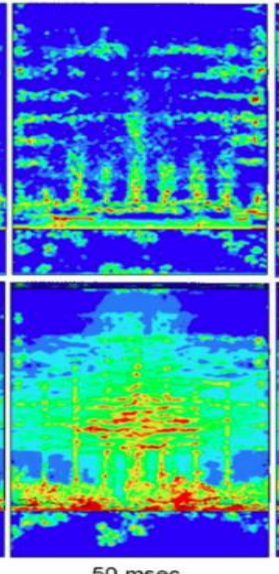

$50 \mathrm{msec}$

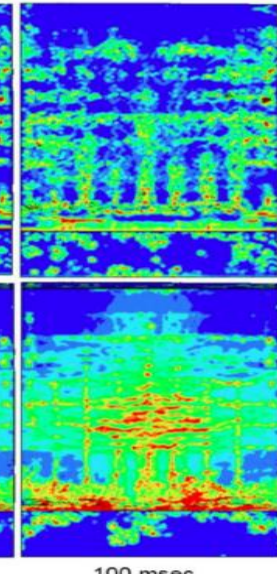

$100 \mathrm{msec}$

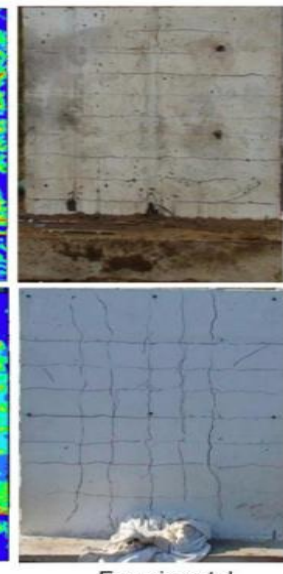

Experimental

Fig. 14. Damage indicator-time history

\section{CONCLUSION}

In this paper numerical simulation has been performed to simulate the blast propagation and pressure study on the cantilevered RC wall and surrounding area. A comparison is made between empirical, numerical and experimental. According to the numerical result presented in the paper, it is found that the highest pressure is observed at the bottom height and followed by the pressure at middle height and top height on the wall surface. Contrary, the blast pressure distribution on the wall surface for the empirical is identical either at the top or bottom surface, where the highest pressure at the middle height on the wall surface. This is because the capability of the numerical analysis to couple different solver together in space and time, where the consideration of complicity of the flow process involved in forming blast wave, obstruction and its interaction.

\section{REFERENCES}

1. H. L. Brode, "Numerical Solution of Spherical Waves", J. Appl. Physic, vol. 26, 1955, pp. 766-775.

2. N. M. Newmark and R. J. Hansen in Design of blast resistant structure, Shock and Vibration Handbook New Jersey, USA: McGraw-Hill, 1961

3. J. Henrych, The dynamic of explosion and its use. Elsevier Scientific Publishing Company, 1979

4. C. N. Kingery and G. Bulmash Air Blast Parameters from TNT Spherical Air Burst and Hemispherical Surface Burst Aberdeen:US Army Research Center-Ballistic Laboratory, 1984.

5. C. A. Mills, "The design of concrete structure to resist explosion and weapon effects", Proc. $1^{\text {st }}$ Int. Conf. on Concrete for Hazard Protections, 1987, pp. 61-73.

6. P. D. Smith and J. G. Hetherington, "Blast and ballistic loading of structures", Butterworth-Heinemann, 1994
7. DOD Unified facilities criteria (UFC 3-340-01) - Design and analysis of hardened structures to conventional weapons effeccts. Department of Defense, United States of America, 2002

8. DOD, Unified facilities criteria (UFC 3-340-02) - Structures to resist the effects of accidental. Department of Defense, United States of America, 2008

9. ANSYS User's manual, Release 14. Canonsburg, PA: ANSYS Inc., 2011

10. D. Yan, G. Chen, J. Baird , H. Yin and M. Koenigstein, "Blast Test of Full-Size Wall Barriers Reinforced with Enamel-Coated Steel Rebar", Struct. Congress ASCE, 2011, pp. 1538-1551.

11. T. Ngo, P. Mendis, A. Gupta and J. Ramsay, "Blast Loading and Blast Effects on Structures - An Overview”, Electronic J. Struct. Eng Special Issue: Loading on Structures, 2007, pp. 76-91.

12. A. Remennikov, The state of the art of explosive loads characterisation. Wollongong Uni, 2007.

13. N. Uddin, Blast protection of civil infrastructures and vehicles using composite, part 1: blast threats and blast loading. Cambridge: Woodhead Publishing Ltd., 2010.

14. G. C. May and P. D. Smith, Blast effects on building. London: Thomas Telford, 1995.

15. ASCE Structural design for physical security-state of the practice. American Society of Civil Engineers, 1999

16. M. Johansson and L. Laine, The capacity of buildings to resist severe dynamic loading, part 1: blast wave loading. Karlstad, Sweden, 2007.

17. W. E. Baker, Explosion in Air. University of Texas Press, 1973.

18. N. Lam, P. Mendis and T. Ngo, "Response Spectrum Solutions for Blast Loading", Electron. J. Struct. Eng., vol.4, 2004, pp. 28-44.

19. W. Riedel, K. Thoma and S. Hiermaier, "Numerical analysis using a new macroscopic concrete model for hydrocodes", Proceedings of the International Symposium on Interaction of the Effect of Munitions with Structures, 1999, pp. 315-22.

20. W. Herrman, "Constitutive equation for the dynamic compaction of ductile porous material", Journal Applied Physic, 40, 1969 pp 2490-2499.

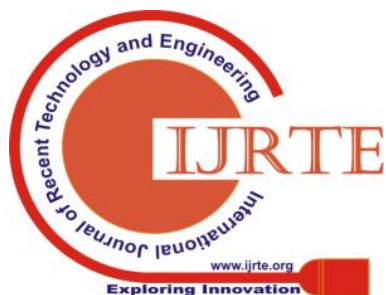


21. G. R. Johnson and W. H. Cook, "A constitutive model and data for metals subjected to large strains, high strain rates and high temperatures", Proceedings of the $7^{\text {th }}$ International Symposium on Ballistic. 1983, pp. 541-548.

22. M. A. Seman, S. M. Syed Mohsin, and M. Z. Jaini, "Blast Load Assessment: RC Wall Subjected to Blast Load", IOP Conf. Series: Earth Environmental Science. 2019

23. G. Chen, R. K. Brow, B. Jason, R. Signo, D. Yan, M. Koenigstein and G. Philip Blast protection of critical infastructure by used of concrete barriers reinforced with enamel coated steel rebar and fibers Missouri:Leonard Wood Institute, 2008

24. N. Kambouchev, L. Noels and R. Radovitzky, "Numerical simulation of the fluid-structure interaction between air blast waves and free-standing plates" Comput. Struct. vol. 85, 2007, pp. 923-931.

\section{AUTHORS PROFILE}

First Author profile which contains their education details, their publications, research work, membership, achievements, with photo that will be maximum 200-400 words.

Second Author profile which contains their education details, their publications, research work, membership, achievements, with photo that will be maximum 200-400 words.

Third Author profile which contains their education details, their publications, research work, membership, achievements, with photo that will be maximum 200-400 words. 